\title{
Evaluation of Optimal Lymph Node Dissection in Remnant Gastric Cancer Based on Initial Distal Gastrectomy
}

\author{
KENTA IGUCHI $^{1,2}$, CHIKARA KUNISAKI ${ }^{1}$, SHO SATO ${ }^{1}$, YUSAKU TANAKA ${ }^{1}$, HIROSHI MIYAMOTO ${ }^{1}$, \\ TAKASHI KOSAKA ${ }^{1}$, HIROTOSHI AKIYAMA ${ }^{3}$, ITARU ENDO ${ }^{3}$, YASUSHI RINO ${ }^{2}$ and MUNETAKA MASUDA ${ }^{2}$ \\ ${ }^{1}$ Department of Surgery, Gastroenterological Center, Yokohama City University Medical Center, Yokohama, Japan; \\ ${ }^{2}$ Department of Surgery, Yokohama City University, School of Medicine, Yokohama, Japan; \\ ${ }^{3}$ Department of Gastroenterological Surgery, Yokohama City University, School of Medicine, Yokohama, Japan
}

\begin{abstract}
Background/Aim: The purpose of this study was to reveal the optimal lymph node $(L N)$ dissection in remnant gastric cancer (RGC) patients. Patients and Methods: We retrospectively analyzed $46 R G C$ patients divided into two groups: patients who underwent initial gastrectomy for benign (group B) and malignant (group $M$ ) diseases. Results: Metastasis was more frequently observed at the left (nos. 2, $4 s a, 4 s b, 10$, and $11 \mathrm{p} / \mathrm{d}$ ) and right (nos. 1, 3, 4d, 7, 8a, and $12 a)$ side $L N s$ of $R G C$ in groups $M$ and B. Modified IEBLD scores (frequency of $L N$ metastasis by median survival time of patients with metastatic $L N s)$ were high at station nos. 10 (4.7), 11p/d (4.3/9.9), and 16 (4.3) in group $M$ and nos. 1 (2.1), 7 (1.9) and mesojejunal (3.0) in group B. Conclusion: After lymphadenectomy for initial gastric cancer, lymphatic flow toward the splenic artery was predominant. Therefore, splenectomy with para-aortic $L N$ dissection is an option.
\end{abstract}

Remnant gastric cancer (RGC) is defined as a cancer in the remnant stomach after initial gastrectomy, and its incidence is low (1-3). Some studies have reported the incidence of RGC in approximately $5 \%$ of gastric cancers $(1,2)$. The lymphatic distribution of proximal gastric cancer has been well studied, and several studies have compared the clinicopathological characteristics of RGC with those of proximal gastric cancer (4-7). Despite diagnostic advancements and progress in medical technology, RGC has a poor prognosis. Moreover, optimal surgical treatments have not been established, a major reason of which is a

Correspondence to: Chikara Kunisaki, Department of Surgery, Gastroenterological Center, Yokohama City University, 4-57, Urafune-cho, Minami-ku, Yokohama, 232-0024, Japan. Tel: +81 452615656, Fax: +81 452619492, e-mail: s0714@med.yokohamacu.ac.jp

Key Words: Gastric stump, lymphatic metastasis, lymphadenectomy. clinicopathological diversity of RGC, including surgical procedures for initial diseases and gastrectomies. Some studies have shown that vascular ligation and lymph node (LN) dissection promote lymphangiogenesis via anastomosis at the initial gastrectomy. Furthermore, lymphangiogenesis affects the distribution of $\operatorname{LN}$ metastasis in $\operatorname{RGC}(3,8)$. However, no optimal method and field of LN dissection for RGC have been established because of its diversity. The optimal LN dissection for RGC is not described in the Japanese Gastric Cancer Treatment Guidelines (English edition, ver. 4) (9).

Thus, the diversity of the lymphatic flow of RGC principally depends on the degree of LN dissection and the reconstruction method of the initial gastrectomy. Recently, gastrectomy for benign gastric disease has remarkably decreased because of developments in medical treatments. Therefore, establishing a surgical strategy for patients undergoing initial gastrectomy with $\mathrm{LN}$ dissection for gastric cancer is important. The aim of this study was to evaluate the optimal LN dissection for RGC on the basis of type of gastrectomy, particularly after initial gastrectomy for gastric cancer.

\section{Materials and Methods}

Study subjects. According to the Japanese Classification of Gastric Carcinoma (English edition, ver. 3) (10), RGC is defined as a cancer in the remnant stomach after distal gastrectomy, irrespective of the histology of the primary lesion (benign/malignant) or its risk of recurrence, extent of resection, or method of reconstruction in this study. A total of 48 patients, who underwent total remnant gastrectomy for RGC at the Department of Surgery Gastroenterological Center, Yokohama City University, between May 1993 and December 2015, were enrolled, of which two were excluded because one underwent pancreaticoduodenectomy with partial gastrectomy for pancreatic cancer and the other underwent proximal gastrectomy with jejunal interposition reconstruction for gastric cancer. Finally, 46 patients were included and divided into two groups: primary surgery for benign disease (group B, 22 patients 
Table I. Comparison of clinicopathological factors according to the initial gastrectomy.

\begin{tabular}{|c|c|c|c|}
\hline & $\begin{array}{c}\text { Group M } \\
(\mathrm{n}=24)\end{array}$ & $\begin{array}{c}\text { Group B } \\
(\mathrm{n}=22)\end{array}$ & $p$-Value \\
\hline \multicolumn{4}{|l|}{ Gender $(\%)$} \\
\hline Male & $20(83.3)$ & $20(90.1)$ & \multirow[t]{2}{*}{0.667} \\
\hline Female & $4(16.7)$ & $2(9.1)$ & \\
\hline \multicolumn{4}{|l|}{ Age (years) } \\
\hline Median (range) & $70(55-87)$ & $66(57-82)$ & 0.392 \\
\hline \multicolumn{4}{|l|}{ Body mass index } \\
\hline Median (range) & $19.9(14.3-25.8)$ & $21.9(16.1-26.8)$ & 0.021 \\
\hline \multicolumn{4}{|l|}{ Interval (years) } \\
\hline Median (range) & $8(1-31)$ & $42(17-59)$ & $<0.001$ \\
\hline \multicolumn{4}{|c|}{ Reconstruction Method (\%) } \\
\hline Billroth-I & $21(87.5)$ & $6(27.3)$ & \multirow{2}{*}{$<0.001$} \\
\hline Billroth-II & $3(12.5)$ & $16(72.7)$ & \\
\hline \multicolumn{4}{|l|}{ Region of tumor $(\%)$} \\
\hline Anastomotic site & $5(20.8)$ & $12(54.5)$ & \multirow[t]{3}{*}{0.036} \\
\hline Suture site & $4(16.7)$ & $4(18.2)$ & \\
\hline Other & $15(62.5)$ & $6(27.3)$ & \\
\hline \multicolumn{4}{|l|}{ Histology (\%) } \\
\hline Differentiated & $15(62.5)$ & $12(54.5)$ & \multirow[t]{2}{*}{0.584} \\
\hline Undifferentiated & $9(37.5)$ & $10(45.5)$ & \\
\hline \multicolumn{4}{|c|}{ Tumor diameter (mm) } \\
\hline Median (range) & $38(14-94)$ & $42(15-160)$ & 0.231 \\
\hline
\end{tabular}

(47.8\%)) and for malignant disease (group M, 24 patients (52.2\%)). Clinicopathological characteristics were retrospectively determined based on their medical records. Tumors and LNs of the stomach were defined according to the Japanese Classification of Gastric Carcinoma (English edition, ver. 3) (10). LNs were classified according to the Japanese Gastric Cancer Treatment Guidelines (English edition, ver. 4) (9). Histological types were classified into two groups: differentiated (papillary, moderately, or well-differentiated carcinoma) and undifferentiated (poorly or undifferentiated adenocarcinoma, signet ring cell carcinoma, and mucinous adenocarcinoma). Tumor locations were divided into three groups depending on the method of initial surgery: anastomosis, suture, and non-anastomosis or nonsuture. All postoperative complications were defined according to the Clavien-Dindo Classification, and grade II or higher was marked as major complications (11).

Evaluation of LN dissection efficacy. To assess the efficacy of LN dissection, the index of estimated benefit from LN dissection (IEBLD) has been used (12). In this study, modified IEBLD score was calculated by multiplying the frequency of $\mathrm{LN}$ metastasis to each station by the median survival time of patients with metastatic LNs at each station.

Statistical analysis. Statistical analysis was performed using the Student's $t$-test for continuous variables with parametric distribution and Mann-Whitney $U$-test for variables with non-parametric distribution. The chi-square and Fisher's exact probability tests were used for the analysis of proportion. Survival curves were plotted using the Kaplan-Meier method and compared using the log rank test. $p$-Value $<0.05$ was considered statistically significant.
Table II. Operative, postoperative and pathological findings according to the initial gastrectomy.

\begin{tabular}{|c|c|c|c|}
\hline & $\begin{array}{c}\text { Group M } \\
(\mathrm{n}=24)\end{array}$ & $\begin{array}{c}\text { Group B } \\
(\mathrm{n}=22)\end{array}$ & $p$-Value \\
\hline \multicolumn{4}{|l|}{ Operative findings } \\
\hline \multicolumn{4}{|l|}{ Operation time (min) } \\
\hline Median (range) & $300(166-640)$ & $242(133-618)$ & 0.06 \\
\hline \multicolumn{4}{|l|}{ Bleeding (ml) } \\
\hline Median (range) & $497(182-3983)$ & $430(35-2600)$ & 0.316 \\
\hline \multicolumn{4}{|l|}{$\begin{array}{l}\text { Number of } \\
\text { dissected lymph nodes }\end{array}$} \\
\hline Median (range) & $10(0-39)$ & $22(0-47)$ & 0.02 \\
\hline Lymphadenectomy (\%) & & & 0.09 \\
\hline D1 & 11 & 4 & \\
\hline D2 & 10 & 16 & \\
\hline \multicolumn{4}{|l|}{$\mathrm{D} 2+$ para-aortic } \\
\hline lymph node dissection & 3 & 2 & \\
\hline Splenectomy (\%) & & & 0.361 \\
\hline Yes & $17(70.8)$ & $12(54.5)$ & \\
\hline No & $7(29.2)$ & $10(45.5)$ & \\
\hline Pancreatectomy (\%) & & & 0.268 \\
\hline Yes & $5(20.8)$ & $2(9.1)$ & \\
\hline No & $19(79.2)$ & $20(90.9)$ & \\
\hline Curability (\%) & & & 0.775 \\
\hline R0 & $20(83.3)$ & $19(86.4)$ & \\
\hline $\mathrm{R} 1 / \mathrm{R} 2$ & $4(16.7)$ & $3(13.6)$ & \\
\hline \multicolumn{4}{|l|}{ Postoperative course } \\
\hline Major complications (\%) & & & 0.734 \\
\hline Pancreatic fistula & $5(20.8) /$ & $6(27.3) /$ & \\
\hline Yes/No & $19(79.2)$ & $16(72.7)$ & \\
\hline Anastomotic leakage & $2(8.3) /$ & $1(4.5) /$ & \\
\hline Yes/No & $22(91.7)$ & $21(95.5)$ & \\
\hline Ileus & $1(4.2) /$ & $0(0) /$ & \\
\hline Yes/No & $23(95.8)$ & $22(100)$ & \\
\hline Abdominal abscess & $1(4.2) /$ & $0(0) /$ & \\
\hline Yes/No & $23(95.8)$ & $22(100)$ & \\
\hline \multicolumn{4}{|l|}{ Hospital stay } \\
\hline Median (range) & $21(11-105)$ & $15(10-213)$ & 0.751 \\
\hline Adjuvant chemotherapy (\%) & & & 0.268 \\
\hline Yes & $5(20.8)$ & $2(9.1)$ & \\
\hline No & $19(79.2)$ & $20(90.9)$ & \\
\hline \multicolumn{4}{|l|}{ Pathological findings } \\
\hline $\mathrm{pT}(\%)$ & & & 0.616 \\
\hline $\mathrm{T} 1$ & $9(37.5)$ & $8(36.4)$ & \\
\hline $\mathrm{T} 2$ & $4(16.7)$ & $2(9.1)$ & \\
\hline $\mathrm{T} 3$ & $4(16.7)$ & $7(31.8)$ & \\
\hline $\mathrm{T} 4$ & $7(29.2)$ & $5(22.7)$ & \\
\hline $\mathrm{pN}(\%)$ & & & 0.930 \\
\hline No & $18(75.0)$ & $18(81.8)$ & \\
\hline $\mathrm{N} 1$ & $2(8.3)$ & $1(4.5)$ & \\
\hline $\mathrm{N} 2$ & $3(12.5)$ & $2(9.1)$ & \\
\hline N3 & $1(4.2)$ & $1(4.5)$ & \\
\hline pStage $(\%)$ & & & 0.278 \\
\hline I & $13(54.2)$ & $10(45.5)$ & \\
\hline II & $4(16.7)$ & $9(40.9)$ & \\
\hline III & $5(20.8)$ & $2(9.1)$ & \\
\hline IV & $2(8.3)$ & $1(4.5)$ & \\
\hline
\end{tabular}




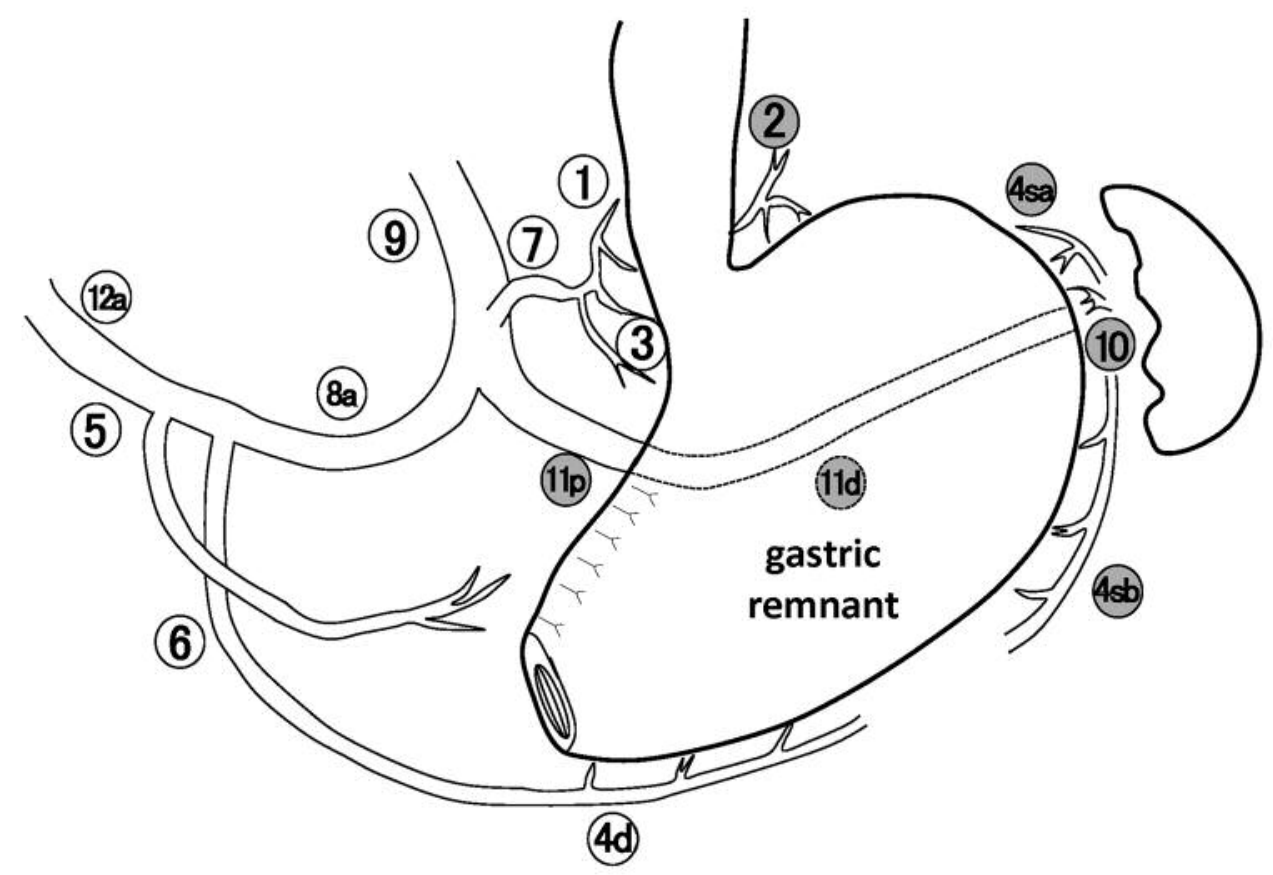

Figure 1. The schema of LN station of RGC. Left side LNs of RGC are shaded.

\section{Results}

Patient characteristics. Clinicopathological characteristics of patients are summarized in Table I. Body mass index was significantly lower and interval from the initial gastrectomy was shorter in group $M$ than in group B. The Billroth-I reconstruction method and tumors in non-anastomotic and non-suture sites were frequent in group M. Other factors did not differ between the two groups.

Surgical outcomes. Surgical outcomes and pathological results of RGCs are summarized in Table II. All patients underwent total gastrectomy with the Roux-en-Y (RY) reconstruction method. D2 lymphadenectomy was performed in 31 (67.4\%) patients, of which five, who were preoperatively suspected of metastasis of para-aortic LNs, underwent para-aortic LN dissection, and remaining $15(32.6 \%)$ underwent D1 lymphadenectomy. In patients receiving the Billroth-II reconstruction method, mesojejunal LNs were routinely resected to dissect LNs along the first jejunal artery. Splenectomy was employed for patients with advanced gastric cancer irrespective of initial gastrectomy. Combined splenectomy was performed in $29(63.0 \%)$ patients, and distal pancreatosplenectomy was performed in seven $(15.2 \%)$. There was no significant difference in the incidence of combined splenectomy and pancreatosplenectomy between the groups. Of the 46 patients included, R0 resection was performed in 39 $(84.8 \%)$. Operation time was longer and the number of dissected LNs was significantly lower in group $\mathbf{M}$ than in group B. Adjuvant chemotherapy was performed in seven $(15.2 \%)$ patients.

Pathological findings. LN metastasis was observed in six $(25.0 \%)$ patients in group $\mathrm{M}$ and in four $(18.2 \%)$ patients in group B. LN metastasis with pT3 or pT4 tumors was detected in $10(21.7 \%)$ patients, whereas that with pT1 or pT2 tumors was not detected in any patient. Pathological staging did not differ between the groups.

Site of metastatic LNs. Figure 1 shows the schema of LN station of RGC, and Table III shows the incidence of metastatic LNs. Metastatic LN sites were divided into the right (nos. 1, 3, 4d, 7, 8a, 12a) and left (nos. 2, 4sa, 4sb, 10, 11p/d) side groups. The celiac artery (no. 9) and para-aortic (no. 16) LNs were separately examined. In group M, metastatic LNs were more frequently observed at the left side stations. However, LN metastases in nos. 1 and 3 were also observed in one patient. In contrast, in group B, LN metastasis was frequent at the right side stations. All metastatic LNs were observed in patients with advanced RGC.

Comparison of efficacy of $L N$ dissection between the groups. Modified IEBLD scores of each LN station between the groups are summarized in Table IV. We examined the number of patients with LN metastasis and the incidence of metastatic LNs at each LN station. The number of patients 
Table III. Lymph node metastasis according to the initial gastrectomy.

\begin{tabular}{lccc}
\hline Station No. & \multicolumn{2}{c}{$\begin{array}{c}\text { Number of patients with } \\
\text { metastatic lymph node (\%) }\end{array}$} & \\
\cline { 2 - 3 } & $\begin{array}{c}\text { Group M } \\
(\mathrm{n}=24)\end{array}$ & $\begin{array}{c}\text { Group B } \\
(\mathrm{n}=22)\end{array}$ & \\
\hline Right side $(1,3,4 \mathrm{~d}, 7,8 \mathrm{a}, 12 \mathrm{a})$ & $1 / 11(9.1)$ & $4 / 22(18.2)$ & 0.492 \\
Left side $(2,4 \mathrm{sa}, 4 \mathrm{sb}, 10,11 \mathrm{p} / \mathrm{d})$ & $5 / 24(20.8)$ & $2 / 22(9.1)$ & 0.268 \\
9 & $1 / 4(25.0)$ & $0 / 14(0)$ & 0.222 \\
16 & $1 / 3(33.3)$ & $0 / 2(0)$ & 0.361 \\
Mesojejunum & $1 / 3(33.3)$ & $2 / 16(12.5)$ & 0.364 \\
\hline
\end{tabular}

with plural metastatic LN stations was calculated redundantly in this study. In group $\mathrm{M}$, modified IEBLD scores of nos. $10,11 \mathrm{p} / \mathrm{d}$, and 16 were high and those of nos. 1 and 3 were low. In contrast, in group B, the scores of nos. 1 and 7 were high. The metastatic rate of mesojejunal LN was $15.8 \%$ in patients receiving Billroth II reconstruction method for primary gastrectomy, which did not differ between the groups.

Survival time. The 5-year OS did not differ between the groups (group M, 69.2\% vs. group B, 58.6\%; p=0.952) (Figure 2).

Patient characteristics with/without splenectomy. In the splenectomy group, younger patients, longer operation time, greater number of dissected LNs, and higher incidence of pancreatic fistula were significantly frequent (Table V).

\section{Discussion}

This study revealed that the lymphatic flow of RGC depends on initial surgery including LN dissection and reconstruction methods. The lymphatic flow along the splenic artery may be predominant in RGC after gastric cancer surgery. RGC has clinicopathological diversity, and the prognosis remains poor $(4,13)$, which may be because RGC patients have poor subjective symptoms. As a result, most patients get diagnosed at an advanced stage (14). Furthermore, the treatment strategy depends on the type of initial gastrectomy, including LN dissection, and the reconstruction method (13, $15,16)$. Thus, because of the clinicopathological diversity of RGC, an efficacious treatment strategy is necessary. Evaluating the lymphatic flow of RGC to establish an optimal LN dissection area is also important.

In the present study, operation interval from initial gastrectomy to surgery for RGC was significantly shorter in group $\mathbf{M}$ than in group $\mathbf{B}$, which is consistent with that observed in previous studies $(17,18)$. Although operation time was longer, the number of dissected LNs was significantly

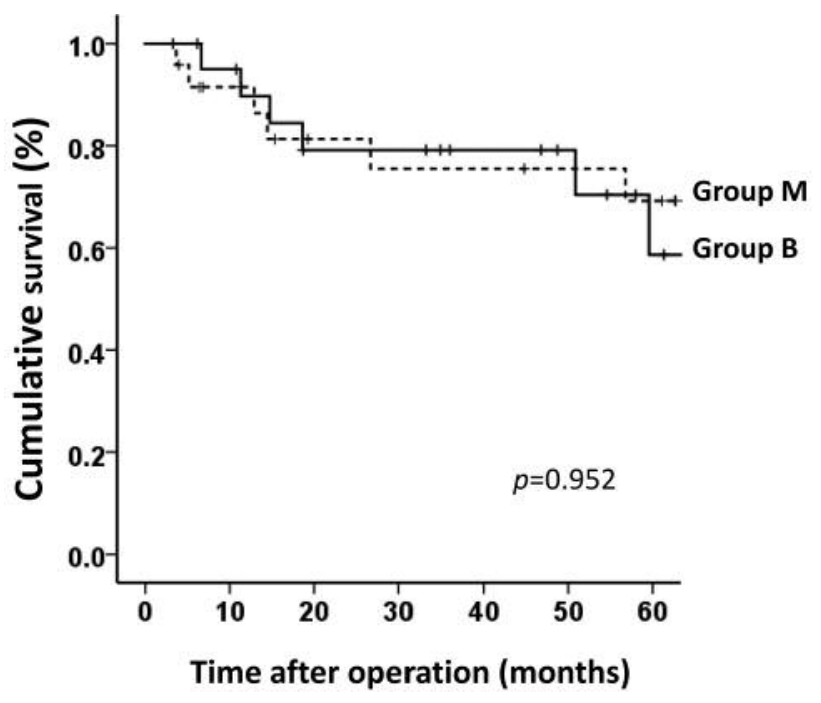

Figure 2. Survival times between groups $M$ and $B$. There was no significant difference between the two groups $(p=0.952)$.

lower in group $\mathrm{M}$, which was considered to be related to $\mathrm{LN}$ dissection of primary gastrectomy. Several studies have shown duodenogastric reflux as the most important factor for the pathogenesis of RGC. However, precancerous lesions such as those in Helicobacter pylori infection (that existed before the initial surgery) have been reported for cases of RGC after gastric cancer surgery $(13,19,20)$.

For years now, surgical treatments for benign disease have dramatically decreased because of advances in medical technology and appearance of new drugs, such as proton pomp inhibitors $(13,21)$. We considered that the ratio of RGC patients after gastrectomy for malignant tumor to all RGC patients would yearly increase. Thus, the treatment strategy for RGC after initial gastrectomy with LN dissection would be more important. According to our results, LN metastasis was only shown in advanced RGC with pT3/pT4 tumors. Therefore, regular checkup for RGC and early detection may improve the prognosis of RGC.

The lymphatic distribution of RGC has several pathways, including celiac artery and abdominal aorta pathway through the blood stream from left gastric artery of lesser curvature and splenic artery pathway from short gastric artery, posterior gastric artery, and left gastroepiploic artery of greater curvature. Furthermore, anastomosis, suture, and adhesion due to primary surgery make extraordinary lymphatic pathway (3, $17,22,23)$. One of these pathways is a mesenteric $\mathrm{LN}$ pathway that is formed by gastrojejunal anastomosis $(3,22$, 24). In our study, mesenteric LN metastasis was observed in three patients, with a high incidence (Table III). Further, these patients received Billroth II reconstruction method for primary 
Table IV. Comparison of efficacy for lymph node dissection to each station.

\begin{tabular}{|c|c|c|c|c|c|c|}
\hline \multirow[b]{2}{*}{ Station No. } & \multicolumn{3}{|c|}{ Group M $(n=24)$} & \multicolumn{3}{|c|}{ Group B $(n=22)$} \\
\hline & $\begin{array}{l}\text { Patients with metastatic } \\
\text { lymph node }(\%)\end{array}$ & $\begin{array}{l}\text { Mean survival } \\
\text { time (month) }\end{array}$ & $\begin{array}{l}\text { Modified IEBLD } \\
\text { score }\end{array}$ & $\begin{array}{l}\text { Patients with metastatic } \\
\text { lymph node }(\%)\end{array}$ & $\begin{array}{l}\text { Mean survival } \\
\text { time (month) }\end{array}$ & $\begin{array}{l}\text { Modified IEBLD } \\
\text { score }\end{array}$ \\
\hline 1 & $1 / 9$ & 3.7 & 0.41 & 3/21 (14.3) & 14.8 & 2.1 \\
\hline 2 & $0 / 24(0)$ & 0 & 0 & $2 / 22(9.1)$ & 13 & 1.2 \\
\hline 3 & $1 / 6(16.7)$ & 3.7 & 0.62 & $1 / 21(4.8)$ & 11.3 & 0.5 \\
\hline $4 \mathrm{sa}$ & $2 / 18(11.1)$ & 4.4 & 0.49 & $1 / 17(5.9)$ & 11.3 & 0.67 \\
\hline $4 \mathrm{sb}$ & $1 / 11(9.1)$ & 5.2 & 0 & $1 / 17(5.9)$ & 11.3 & 0.67 \\
\hline $4 d$ & $0 / 1(0)$ & 0 & 0 & $0 / 6(0)$ & 0 & 0 \\
\hline 7 & $0 / 0(0)$ & 0 & 0 & $1 / 19(5.3)$ & 36 & 1.9 \\
\hline $8 \mathrm{a}$ & $0 / 0(0)$ & 0 & 0 & $0 / 16(0)$ & 0 & 0 \\
\hline 9 & $1 / 4(25.0)$ & 3.7 & 0.93 & $0 / 14(0)$ & 0 & 0 \\
\hline 10 & $3 / 17(17.6)$ & 26.7 & 4.7 & $0 / 12(0)$ & 0 & 0 \\
\hline $11 p$ & $2 / 14(14.3)$ & 30.2 & 4.3 & $1 / 14(7.1)$ & 14.8 & 1.1 \\
\hline $11 \mathrm{~d}$ & $2 / 12(16.7)$ & 59.3 & 9.9 & $0 / 11(0)$ & 0 & 0 \\
\hline $12 \mathrm{a}$ & $0 / 2(0)$ & 0 & 0 & $0 / 4(0)$ & 0 & 0 \\
\hline Mesojejunum & $1 / 3(33.3)$ & 5.1 & 1.7 & $2 / 16(12.5)$ & 23.6 & 3.0 \\
\hline 16 & $1 / 3(33.3)$ & 12.9 & 4.3 & $0 / 2(0)$ & 0 & 0 \\
\hline
\end{tabular}

gastrectomy. Thus, considering such an abnormal lymphatic pathway and metastasis to mesenteric $\mathrm{LN}$, patients undergoing remnant gastrojejunostomy with the Billroth II or RY method should be considered for performing lymphadenectomy of jejunum mesenteric LNs.

The incidence of metastases to left-side LNs was higher in group $\mathrm{M}$ than in group $\mathrm{B}$. The difference is related to the presence or absence of $\mathrm{LN}$ dissection of the initial surgery. Lymphatic flow from lesser curvature is blocked particularly in patients who underwent LN dissection around the left and right gastric artery for primary gastrectomy $(5,22,25)$. As a result, the lymphatic distribution of greater curvature becomes predominant in such patients, which should be taken into account when determining the range of lymphadenectomy in RGC patients who underwent initial gastrectomy for gastric cancer. Hence, splenic hilum and splenic artery LN (station nos. 10 and 11) should be considered, particularly in patients undergoing initial gastrectomy for gastric cancer. Earlier studies have reported that metastasis to splenic hilar and splenic artery LN is more frequent in RGC than in primary cancer at the upper third of stomach $(5,26)$. Our study showed that the ratio of LN metastases of the splenic hilum and along the splenic artery was higher in group $M$ than in group B. Further, there was no patient with LN metastasis along the common hepatic arteries in group $\mathbf{M}$. Our results also showed a high efficacy of LN dissection along the splenic artery and abdominal aorta in group $\mathrm{M}$. Thus, lymphatic flow toward the splenic artery becomes dominant in patients who undergo initial gastrectomy for
Table V. Comparison of clinical factors in patients with and without splenectomy.

\begin{tabular}{|c|c|c|c|}
\hline & $\begin{array}{l}\text { Splenectomy } \\
\quad(\mathrm{n}=29)\end{array}$ & $\begin{array}{l}\text { Non-Splenectomy } \\
(\mathrm{n}=17)\end{array}$ & $\mathrm{p}$-Value \\
\hline \multicolumn{4}{|l|}{ Gender (\%) } \\
\hline Male & $26(89.7)$ & $14(82.4)$ & 0.655 \\
\hline Female & $3(10.3)$ & $3(17.6)$ & \\
\hline \multicolumn{4}{|l|}{ Age (years) } \\
\hline Median (range) & $68(55-80)$ & $76(61-87)$ & 0.010 \\
\hline Initial gastrectomy & & & 0.361 \\
\hline Group M & 17 & 7 & \\
\hline Group B & 12 & 10 & \\
\hline \multicolumn{4}{|l|}{ Operation time (min) } \\
\hline Median (range) & $300(182-640)$ & $223(133-481)$ & 0.011 \\
\hline \multicolumn{4}{|c|}{ Bleeding volume (ml) } \\
\hline Median (range) & $650(35-3983)$ & $350(90-1918)$ & 0.054 \\
\hline \multicolumn{4}{|l|}{$\begin{array}{l}\text { Number of dissected } \\
\text { lymph nodes }\end{array}$} \\
\hline Median (range) & $16(0-47)$ & $12(0-34)$ & 0.041 \\
\hline \multicolumn{4}{|l|}{ Pancreatic fistula } \\
\hline Yes & $10(34.5)$ & $1(5.9)$ & 0.036 \\
\hline No & $19(65.5)$ & $16(9.4)$ & \\
\hline \multicolumn{4}{|l|}{ Hospital stay (day) } \\
\hline Median (range) & $21(12-213)$ & $17(13-108)$ & 0.621 \\
\hline
\end{tabular}

gastric cancer. Therefore, splenectomy and para-aortic LN dissection may be an important option in these patients.

Whether splenectomy is required during surgery for the treatment of RGC is a key issue. JCOG0110 trial, which 
examined the importance of splenectomy in patients with advanced gastric cancer, showed that splenectomy is an option if tumor is located at a greater curvature (27). In contrast, several reports have reported the complications of splenectomy, one of which is the risk of compromised immune function, which sometimes causes serious or life-threatening infections. Furthermore, splenectomy carries the potential risk of bleeding and injury to nearby organs $(2,28,29)$. In this study, patients with splenectomy had large blood loss and the surgery time was significantly longer than those without splenectomy. Thus, combined organ resection is more invasive for patients. Similarly, the indications for para-aortic LN dissection should be carefully considered (30). Therefore, gastric surgeons should determine the extent of LN dissection according to the background of patients and select patients tolerant to splenectomy and para-aortic lymph node dissection $(30,31)$. In the present study, metastatic LNs were shown only in patients with pT3/4 advanced RGC, and several studies have reported that $\mathrm{LN}$ metastasis is not frequently observed in early $\operatorname{RGC}(5,21,25)$. Moreover, our study revealed that lymphatic flow along the splenic artery is predominant in group $\mathrm{M}$. These results indicated that splenectomy is an option for patients with advanced RGC who underwent initial gastrectomy for gastric cancer. Further, the impact of splenectomy was quite low in patients with early RGC who received initial gastrectomy for gastric cancer.

The limitations of this study included the small sample size and retrospective and single-institution design. Therefore, it is necessary to conduct future studies with large sample sizes in multiple institutions.

In conclusion, this study showed alterations in the lymphatic flow and lymphangiogenesis according to $\mathrm{LN}$ dissection and the reconstruction method of initial gastrectomy. Therefore, it is necessary to employ optimal LN dissection for RGC surgery according to the type of initial distal gastrectomy. Particularly, LN dissection along the splenic artery, including splenectomy with/without paraaortic LN dissection, is appropriate in patients receiving initial distal gastrectomy for gastric cancer. However, future studies with large sample sizes are required.

\section{Acknowledgements}

The Authors would like to thank Dr. Yoshiaki Inayama from the Department of Diagnostic Pathology at Yokohama City University Medical Center, who provided carefully considered feedback and valuable comments.

\section{References}

1 Kaneko K, Kondo H, Saito D, Shirao K, Yamaguchi H, Yokota T, Yamao G, Sano T, Sasako M and Yoshida S: Early gastric stump cancer following distal gastrectomy. Gut 43: 342-344, 1998.
2 Yamamoto M, Baba H, Kakeji Y, Endo K, Ikeda Y, Toh Y, Kohnoe S, Okamura T and Maehara Y: Postoperative morbidity/ mortality and survival rates after total gastrectomy, with splenectomy/pancreaticosplenectomy for patients with advanced gastric cancer. Hepatogastroenterology 51: 298-302, 2004.

3 Han K Bin, Jang YJ, Kim JH, Park SS, Park SH, Kim SJ, Mok YJ and Kim CS: Clinical significance of the pattern of lymph node metastasis depending on the location of gastric cancer. $\mathrm{J}$ Gastric Cancer 11: 86-93, 2011.

4 Thorban S, Böttcher K, Etter M, Roder JD, Busch R and Siewert JR: Prognostic factors in gastric stump carcinoma. Ann Surg 231: 188-194, 2000.

5 Imada T, Rino Y, Hatori S, Shiozawa M, Takahashi M, Amano T, Kondo J, Kobayashi O, Sairenji M and Motohashi $\mathrm{H}$ : Clinicopathologic differences between early gastric remnant cancer and early primary gastric cancer in the upper third of the stomach. Hepatogastroenterology 47: 1186-1188, 2000.

6 An JY, Choi MG, Noh JH, Sohn TS and Kim S: The outcome of patients with remnant primary gastric cancer compared with those having upper one-third gastric cancer. Am J Surg 194: 143147, 2007.

7 Shimada H, Fukagawa T, Haga Y and Oba K: Does remnant gastric cancer really differ from primary gastric cancer? A systematic review of the literature by the Task Force of Japanese Gastric Cancer Association. Gastric Cancer 19: 339349, 2016.

8 Safatle-Ribeiro AV, Ribeiro U, Reynolds JC, Gama-Rodrigues JJ, Iriya K, Kim R, Bakker A, Swalsky PA, Pinotti HW and Finkelstein SD: Morphologic, histologic, and molecular similarities between adenocarcinomas arising in the gastric stump and the intact stomach. Cancer 78: 2288-2299, 1996.

9 Japanese Gastric Cancer Association: Japanese gastric cancer treatment guidelines 2014 (ver. 4). Gastric Cancer 20: 1-19, 2017.

10 Sano $\mathrm{T}$ and Kodera Y: Japanese classification of gastric carcinoma: 3rd English edition. Gastric Cancer 14: 101-112, 2011.

11 Dindo D, Demartines N and Clavien P-A: Classification of Surgical Complications. Ann Surg 240: 205-213, 2004.

12 Sasako M, McCulloch P, Kinoshita T and Maruyama K: New method to evaluate the therapeutic value of lymph node dissection for gastric cancer. Br J Surg 82: 346-351, 1995.

13 Sasako M, Maruyama K, Kinoshita $\mathrm{T}$ and Okabayashi K: Surgical treatment of carcinoma of the gastric stump. Br J Surg 78: 822-824, 1991

14 Wang Y, Huang C-M, Wang J-B, Zheng C-H, Li P, Xie J-W, Lin $\mathrm{J}-\mathrm{X}$ and $\mathrm{Lu} \mathrm{J}$ : Survival and surgical outcomes of cardiac cancer of the remnant stomach in comparison with primary cardiac cancer. World J Surg Oncol 12: 21, 2014.

15 Xiang H, Tian DY, Liang C and Yu Y: Progression and prognosis of gastric stump cancer. J Surg Oncol 100: 472-476, 2009.

16 Virgilio E, Balducci G, Mercantini P, Ferri M, Bocchetti T, Caterino S, Salvi PF, Ziparo V and Cavallini M: Reconstruction After Distal Gastrectomy for Gastric Cancer: Billroth 2 or RouxEn-Y Procedure? Anticancer Res 37: 5595-5602, 2017.

17 Honda S, Bando E, Makuuchi R, Tokunaga M, Tanizawa Y, Kawamura T, Sugiura T, Kinugasa Y, Uesaka K and Terashima M: Effects of initial disease status on lymph flow following gastrectomy in cases of carcinoma in the remnant stomach. Gastric Cancer 20: 1-8, 2016. 
18 Tanigawa N, Nomura E, Lee S-W, Kaminishi M, Sugiyama M, Aikou $\mathrm{T}$ and Kitajima M: Current state of gastric stump carcinoma in Japan: based on the results of a nationwide survey. World J Surg 34: 1540-1547, 2010.

19 Furukawa H, Iwanaga T, Hiratsuka M, Imaoka S, Ishikawa Kabuto OT, Sasaki V and Kameyama M: Gastric remnant cancer as a metachronous multiple lesion. Br J Surg 80: 54-56, 1993.

20 Onoda N, Maeda K, Sawada T, Wakasa K, Arakawa T and Chung KH: Prevalence of Helicobacter pylori infection in gastric remnant after distal gastrectomy for primary gastric cancer. Gastric Cancer 4: 87-92, 2001.

21 Kodera Y, Yamamura Y, Torii A, Uesaka K, Hirai T, Yasui K, Morimoto T, Kato T and Kito T: Gastric remnant carcinoma after partial gastrectomy for benign and malignant gastric lesions. $\mathrm{J}$ Am Coll Surg 182: 1-6, 1996.

22 Ikeguchi M, Kondou A, Shibata S, Yamashiro H, Tsujitani S, Maeta $\mathrm{M}$ and Kaibara N: Clinicopathologic differences between carcinoma in the gastric remnant stump after distal partial gastrectomy for benign gastroduodenal lesions and primary carcinoma in the upper third of the stomach. Cancer 73: 15-21, 1994.

23 Komatsu S, Ichikawa D, Okamoto K, Ikoma D, Tsujiura M, Shiozaki A, Fujiwara H, Murayama Y, Kuriu Y, Ikoma H, Nakanishi M, Ochiai T, Kokuba Y and Otsuji E: Differences of the Lymphatic Distribution and Surgical Outcomes Between Remnant Gastric Cancers and Primary Proximal Gastric Cancers. J Gastrointest Surg 16: 503-508, 2012.

24 Han SL, Hua YW, Wang CH, Ji SQ and Zhuang J: Metastatic pattern of lymph node and surgery for gastric stump cancer. J Surg Oncol 82: 241-246, 2003

25 Tanigawa N, Nomura E, Niki M, Shinohara H, Nishiguchi K, Okuzawa M, Toyoda M and Morita S: Clinical study to identify specific characteristics of cancer newly developed in the remnant stomach. Gastric Cancer 5: 23-28, 2002.
26 Komatsu S, Ichikawa D, Okamoto K, Ikoma D, Tsujiura M, Nishimura Y, Murayama Y, Shiozaki A, Ikoma H, Kuriu Y, Nakanishi M, Fujiwara H, Ochiai T, Kokuba Y and Otsuji E: Progression of remnant gastric cancer is associated with duration of follow-up following distal gastrectomy. World J Gastroenterol 18: 2832-2836, 2012.

27 Sano T, Sasako M, Mizusawa J, Yamamoto S, Katai H, Yoshikawa T, Nashimoto A, Ito S, Kaji M, Imamura $\mathrm{H}$, Fukushima N, Fujitani K and Stomach Cancer Study Group of the Japan Clinical Oncology Group: Randomized Controlled Trial to Evaluate Splenectomy in Total Gastrectomy for Proximal Gastric Carcinoma. Ann Surg 265: 277-283, 2017.

28 Kitamura K, Nishida S, Ichikawa D, Taniguchi H, Hagiwara A, Yamaguchi T and Sawai K: No survival benefit from combined pancreaticosplenectomy and total gastrectomy for gastric cancer. Br J Surg 86: 119-122, 1999.

29 Ohashi M, Katai H, Fukagawa T, Gotoda T, Sano T and Sasako $\mathrm{M}$ : Cancer of the gastric stump following distal gastrectomy for cancer. Br J Surg 94: 92-95, 2007.

30 Kaito A, Kinoshita T, Tokunaga M, Sunagawa H, Watanabe M, Sugita S, Tonouchi A, Sato R, Abe I and Akimoto T: Prognostic factors and recurrence pattern of far-advanced gastric cancer with pathologically-positive para-aortic lymph nodes. Anticancer Res 37: 3685-3692, 2017.

31 Kawaguchi T, Komatsu S, Ichikawa D, Kimura YU, Komiyama S, Konishi H, Kin S, Kawakami S, Kosuga T, Okamoto K and Otsuji E: Prognostic influence of the extent of lymph node dissection and perioperative comorbidities in patients with gastric cancer. Anticancer Res 36: 1917-1922, 2016.

Received December 11, 2017

Revised December 23, 2017

Accepted December 29, 2017 